\title{
Effect of the cholecystokinin-receptor antagonist lorglumide on pancreatic enzyme secretion stimulated by bombesin, food, and caerulein, giving similar plasma cholecystokinin concentrations in the $\operatorname{dog}$
}

\author{
A J L de Jong, M V Singer, J B M J Jansen, W Niebel, L C Rovati, C B H W Lamers
}

\begin{abstract}
This study was undertaken to determine the role of cholecystokinin in pancreatic enzyme secretion stimulated by bombesin and a meal by ( $a$ ) comparing the pancreatic enzyme output during bombesin infusion and after a meal to output during caerulein infusion and (b) comparing the inhibitory effect of the cholecystokinin-receptor antagonist lorglumide (CR-1409) on enzyme output in response to bombesin and food with the response to caerulein. Bombesin $(90 \mathrm{pmol} / \mathrm{kg}$ per h) and caerulein (30 pmol/kg per $h$ ) were infused into seven dogs in doses giving similar plasma cholecystokinin peak increments as a meal (mean (SEM) 6.8 (0.8), 6.3 (1.2), and $5.7(0.8)$ pM, respectively), together with either saline or $2 \mathrm{mg} / \mathrm{kg}$ per h of lorglumide. A background infusion of synthetic secretin $20.5 \mathrm{pmol} / \mathrm{kg}$ per $h$ was given in each experiment. In addition, gastric acid secretion was determined in the experiments with bombesin and caerulein infusion. Pancreatic protein responses to bombesin (1231 (247) $\mathrm{mg} / \mathrm{h}$ ) and food (1430 (220) $\mathrm{mg} / \mathrm{h}$ ) were similar to the responses to caerulein (1249 (201) $\mathrm{mg} / \mathrm{h})$. Lorglumide inhibited pancreatic protein output during stimulation with bombesin by $60 \%$, after the meal by $45 \%$, and during caerulein infusion by $68 \%$. Pancreatic bicarbonate output by bombesin, caerulein, and food was inhibited by lorglumide by $28 \%, 40 \%$, and $38 \%$, respectively. In contrast, lorglumide significantly increased gastric acid secretion from 1.12 to $7.98 \mathrm{mmol} / \mathrm{h}$ during bombesin infusion and from 0.52 to $7.62 \mathrm{mmol} / \mathrm{h}$ during caerulein infusion. In conclusion, cholecystokinin plays an important part in the stimulation of pancreatic enzyme secretion by bombesin and a meal in conscious dogs and it is involved in the regulation of gastric acid during stimulation by infusions of caerulein and bombesin.
\end{abstract}

Bombesin is a neuropeptide present in the nerves of the gastrointestinal tract including the duodenum and pancreas of several species. Bombesin-like peptides potently stimulate pancreatic enzyme secretion. ${ }^{2-4}$ How bombesin acts on the pancreas has not been fully elucidated. On the one hand, receptors for bombesin have been identified on acinar cells of most species ${ }^{45}$; on the other hand, bombesin is known to stimulate the secretion of several gastrointestinal polypeptides, including the enterohormone cholecystokinin, a powerful stimulant of pancreatic enzyme secretion. ${ }^{36}$

It is generally accepted that food stimulates pancreatic enzyme secretion through a delicate interplay between nerves and gastrointestinal hormones. ${ }^{247}$ Several studies have suggested an important role for the vagal cholinergic system and for cholecystokinin. ${ }^{27}$

The present study was undertaken to determine the role of cholecystokinin in the stimulation of pancreatic enzyme secretion by bombesin and food in the dog by $(a)$ comparing the effects on pancreatic enzyme secretion of similar plasma cholecystokinin concentrations obtained after feeding and after the infusion of bombesin and the synthetic cholecystokininpeptide caerulein and $(b)$ comparing inhibition by the cholecystokinin-receptor antagonist CR1409 (lorglumide) ${ }^{89}$ on bombesin and food stimulated pancreatic enzyme secretion to that during infusion of caerulein. Since the dogs were equipped with a gastric fistula, which was kept open during the studies to prevent acid entering the duodenum, we were also able to study the effect of the cholecystokinin-receptor antagonist on gastric acid during the infusions of caerulein and bombesin.

\section{Methods}

Seven mongrel female dogs, each weighing 17$32 \mathrm{~kg}$, were fitted with a chronic duodenal fistula as described by Thomas and a gastric fistula using a Thomas-type cannula, modified so that the inner flange was circular rather than oval. ${ }^{111}$ The duodenal Thomas cannula was placed opposite the main pancreatic duct, while the accessory pancreatic duct was ligated. Studies were started four weeks after surgery. Food but not water was withheld for 18 hours before each test. In each dog a glass cannula connected to a piece of polyethylene tubing was inserted into the main pancreatic duct and pancreatic juice was collected in ice-cold graduated conical tubes. The duodenal fistula was then closed by putting gauze dipped in soft paraffin around the glass cannula to avoid leakage of duodenal contents. After the gastric cannula was opened and the stomach rinsed with distilled water a polyethylene tube with a diameter of $10 \mathrm{~mm}$ was inserted into the stomach and the fistula was closed in a similar way to the duodenal fistula.

Six experiments, separated by at least one 

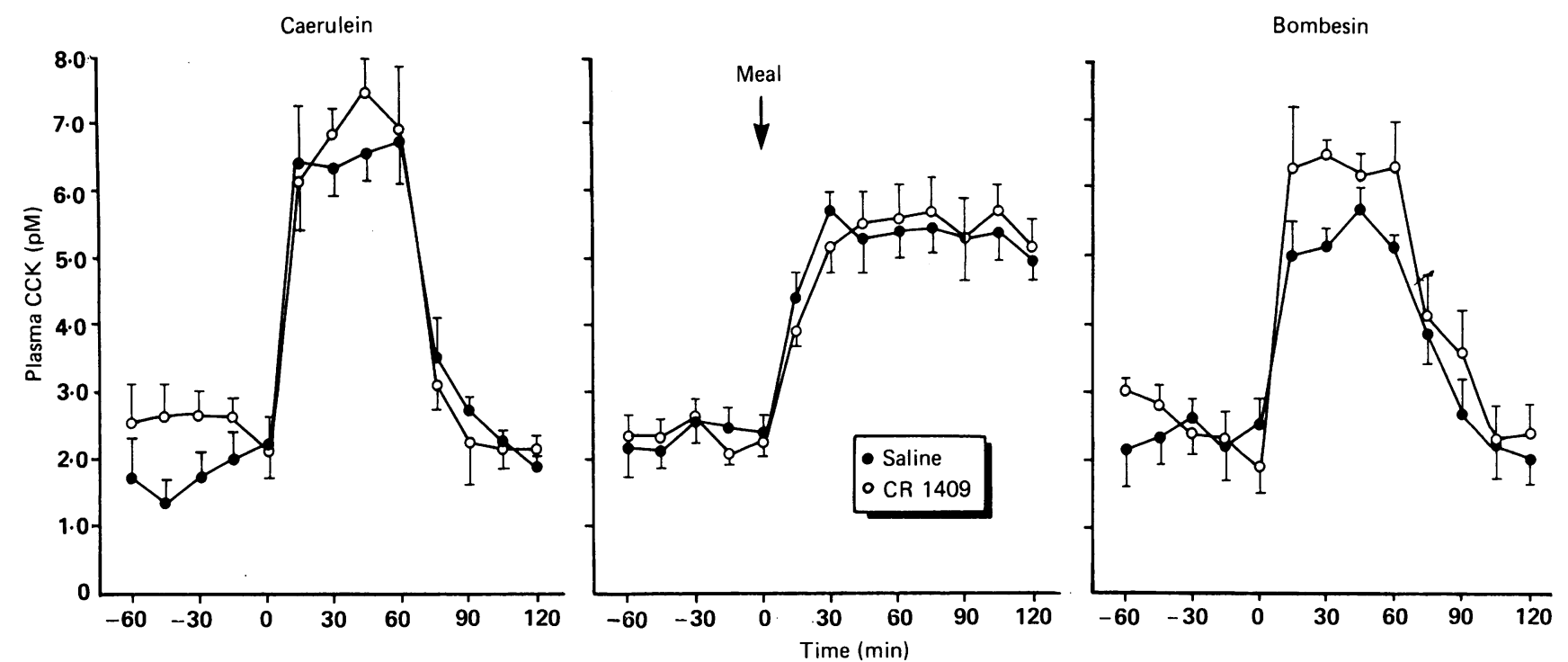

Figure 1: Plasma cholecystokinin (CCK) concentrations (mean (SEM), 7 dogs) during infusion of caerulein (left), intragastric administration of a meal (middle), and bombesin infusion (right) together with an infusion of lorglumide or saline.

week, were performed at random on each of the seven dogs: intragastric administration of a standard test meal and infusions of bombesin and caerulein together with either saline or lorglumide (CR-1409; Rotta Research Laboratories, Monza, Italy) were given. All studies were done with an intravenous of $20.5 \mathrm{pmol} / \mathrm{kg}$ per $\mathrm{h}$ synthetic secretin (Hoechst AB, Frankfurt, FRG) dissolved in $0 \cdot 1 \%$ dog albumin solution, to guarantee sufficiently large volumes of pancreatic juice. In preliminary studies the doses of bombesin (UCB, Brussels, Belgium) and caerulein (Farmitalia, Milan, Italy) were determined to give plasma cholecystokinin concentrations similar to those after the meal. The meal, consisting of $100 \mathrm{~g}$ of liver extract (Murnil) containing $74.3 \mathrm{~g}$ protein and $17.3 \mathrm{~g}$ fat homogenised in $400 \mathrm{ml}$ of water, was instilled through the gastric fistula within 10 minutes to guarantee reproducible responses.

Plasma samples for measurement of cholecystokinin were obtained at 15 minute intervals. Plasma cholecystokinin was measured by a specific and sensitive radioimmunoassay as described previously. ${ }^{12}{ }^{13}$ Antibody T204 was used, which showed equal binding to carboxy-terminal cholecystokinin peptides containing the sulphated tyrosyl region. ${ }^{12+}$ Pancreatic and gastric juice were collected continuously and separated into 15 minute samples. Volume was measured to the nearest $0 \cdot 1 \mathrm{ml}$. Concentrations of protein and bicarbonate were measured as described previously, ${ }^{15}$ while gastric acid concentrations were determined by titration with $0 \cdot 1 \mathrm{M} \mathrm{NaOH}$ to $\mathrm{pH} 7 \cdot 0$.

Results are expressed as mean (SEM). In the three experiments in each dog in which either saline or lorglumide was infused before the stimulants, the mean of the three results for each dog was used for further analysis. Statistical analysis was done by Student's $t$ test for paired results.

\section{Results}

In the 21 experiments in the seven dogs in which either saline or lorglumide was infused with the secretin infusion alone, no significant differences were found in pancreatic protein secretion (201 (54) $v 154(45) \mathrm{mg} / \mathrm{h}$ ) and bicarbonate secretion $(2 \cdot 3(0.5) v 2 \cdot 6(0 \cdot 8) \mathrm{mmol} / \mathrm{h})$.

Plasma cholecystokinin peak increments were similar in response to the three stimulants: $6 \cdot 8$ $(0 \cdot 8) \mathrm{pM}$ during bombesin infusion, $5 \cdot 7(0.8)$
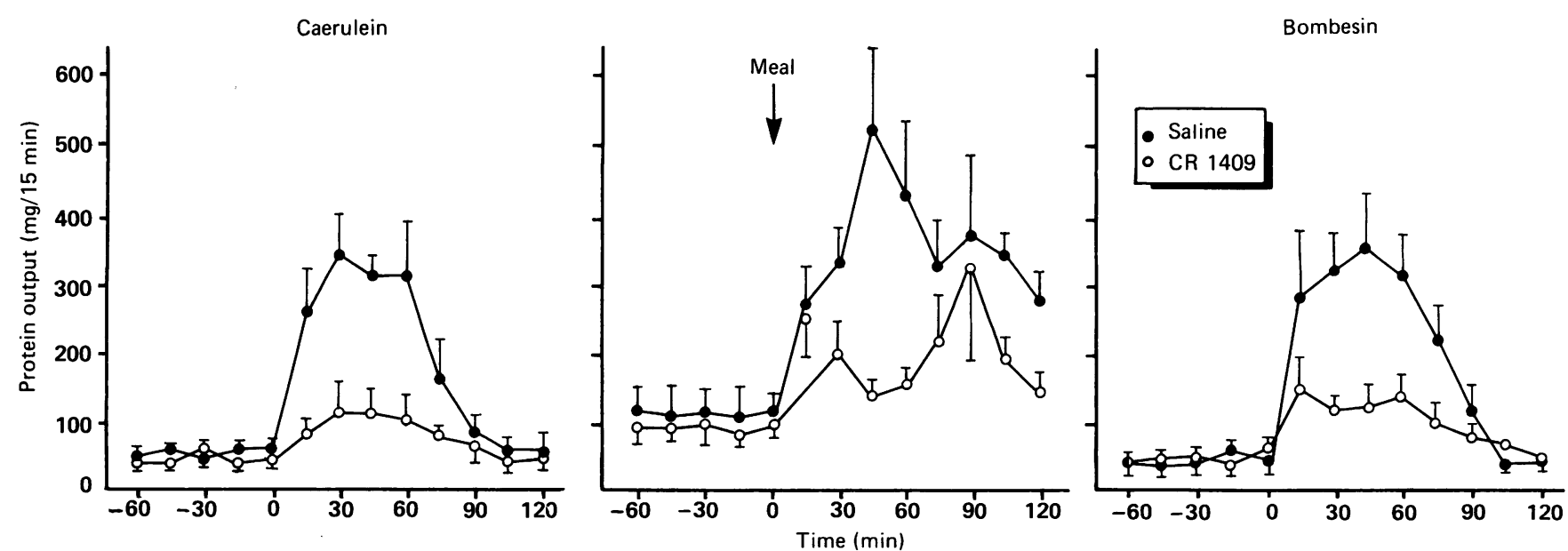

Figure 2: Pancreatic protein output (mean (SEM), 7 dogs) during infusion of caerulein (left), intragastric administration of a meal (middle), and bombesin infusion (right) together with an infusion of lorglumide or saline. 


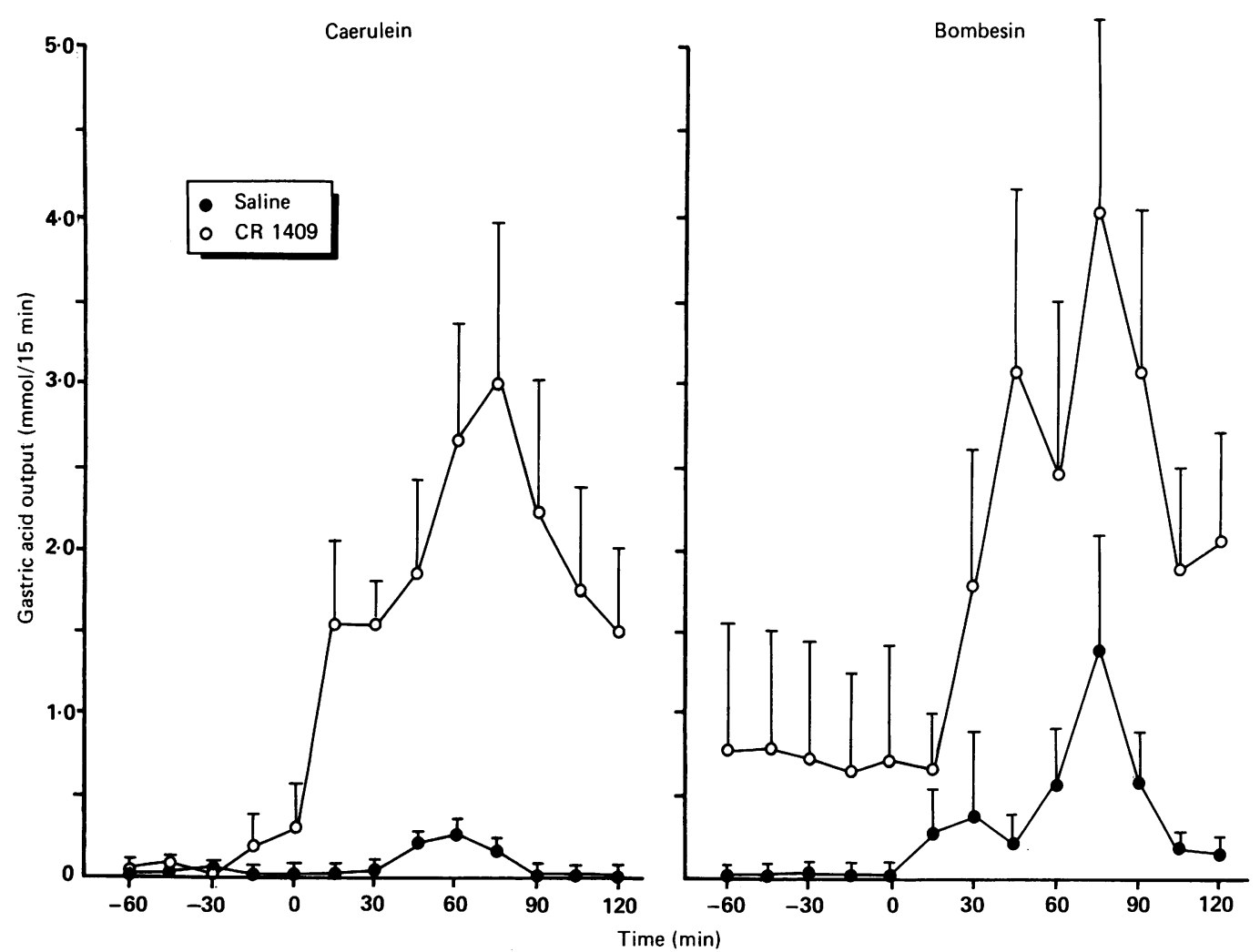

Figure 3: Gastric acid output (mean (SEM), 7 dogs) during infusion of caerulein (left) or bombesin (right) together with an infusion of lorglumide or saline.

pM after the standard test meal, and 6.3(1·2) pM during caerulein infusion (Fig 1).

Infusion of bombesin increased pancreatic protein output from 149 (39) to 1231 (247) mg/h $(\mathrm{p}<0.005)$; the standard test meal increased pancreatic protein secretion from 221 (62) to $1430(220) \mathrm{mg} / \mathrm{h}(\mathrm{p}<0.01)$, and caerulein infusion increased pancreatic protein secretion from 220 (62) to $1249(201) \mathrm{mg} / \mathrm{h}(\mathrm{p}<0.005)$. The pancreatic protein output during bombesin infusion and after the test meal was not significantly different from that during infusion of caerulein (Fig 2). Pancreatic bicarbonate secretion increased from $1.4(0.4)$ to $5.7(1.2) \mathrm{mmol} / \mathrm{h}$ $(\mathrm{p}<0.01)$ during bombesin infusion, from 2.9 $(0.5)$ to $11.8(1.1) \mathrm{mmol} / \mathrm{h}(\mathrm{p}<0.005)$ after the test meal, and from $2 \cdot 3(0.6)$ to $5.9(1.5) \mathrm{mmol} / \mathrm{h}$ $(\mathrm{p}<0.05)$ during caerulein infusion. Pancreatic bicarbonate output after the test meal was significantly greater $(p<0.05)$ than during the infusions. Infusion of bombesin increased gastric acid secretion from 0.05 to $1.12 \mathrm{mmol} / \mathrm{h}$ $(\mathrm{p}<0.05)$, while caerulein infusion induced a non-significant increase from 0.07 to $0.52 \mathrm{mmol} /$ h (Fig 3).

Infusion of lorglumide did not significantly influence basal or stimulated plasma cholecystokinin concentrations (Fig 1). During this infusion pancreatic protein output during bombesin infusion was $495(115) \mathrm{mg} / \mathrm{h}(\mathrm{p}<0.05)$, after the test meal to $788(170) \mathrm{mg} / \mathrm{h}(\mathrm{p}<0.05)$, and during caerulein infusion to $401(131) \mathrm{mg} / \mathrm{h}$ $(\mathrm{p}<0.001$; Fig 2$)$. Inhibition of pancreatic protein output by lorglumide during bombesin infusion $(60 \%)$ and after the test meal $(45 \%)$ was not significantly different from that during caerulein infusion (68\%). During lorglumide infusion pancreatic bicarbonate secretion stimulated by bombesin was inhibited to $4 \cdot 1(0 \cdot 7) \mathrm{mmol} / \mathrm{h}$ (not significant), after the test meal to $7 \cdot 3(1 \cdot 7) \mathrm{mmol} / \mathrm{h}$ $(\mathrm{p}<0.05)$, and during caerulein infusion to 3.5 $(0.9) \mathrm{mmol} / \mathrm{h}$. The relative inhibition of pancreatic bicarbonate output by lorglumide was not significantly different during administration of the three stimuli: $28 \%$ during infusion of bombesin, $38 \%$ after the test meal, and $40 \%$ during caerulein infusion.

Lorglumide increased gastric acid output during caerulein infusion from 0.52 to 7.62 $\mathrm{mmol} / \mathrm{h}(\mathrm{p}<0.05)$ and during bombesin administration from 1.12 to $7.98 \mathrm{mmol} / \mathrm{h}(\mathrm{p}<0.05)$, while the increase in gastric acid output before administration of the stimulants, from 0.08 to $0.58 \mathrm{mmol} / \mathrm{h}$ was not significant (Fig 3 ).

\section{Discussion}

This study shows that, in agreement with other studies, ${ }^{16} 17$ pancreatic protein and bicarbonate output during stimulation with secretin are not affected by the cholecystokinin-receptor antagonist CR-1409 (lorglumide), indicating that cholecystokinin does not play a major part in the regulation of secretin stimulated pancreatic exocrine secretion. The finding, however, that at similar plasma cholecystokinin concentrations induced by the three stimuli, pancreatic protein output during bombesin infusion and after the test meal was not significantly different from that during caerulein infusion suggests that cholecystokinin is an important mediator of pancreatic enzyme secretion during stimulation with bombesin or food. The role of cholecystokinin as mediator of the stimulatory action of bombesin and the test meal on pancreatic enzyme secretion is further supported by the finding that administration of lorglumide, in a dose that inhibited caerulein-stimulated pancreatic enzyme 
secretion by $68 \%$, inhibited the enzyme response to bombesin by $60 \%$ and to the test meal by $45 \%$. Although the percentage inhibition by lorglumide of the pancreatic enzyme response to the test meal was not significantly different from that to caerulein infusion, the relatively lower inhibitory effect of lorglumide on the test meal stimulated enzyme secretion (45\% $v$ 68\%) suggests that, apart from cholecystokinin, other mediators may be involved in the pancreatic enzyme response to the meal. Among these, the importance of vagal cholinergic reflexes from the stomach and upper small intestine to the pancreas has been well established. ${ }^{18-21}$ Our results contrast with those of Pendleton et al, which showed that the non-peptide cholecystokinin-receptor antagonist L-364,718 did not affect postprandial pancreatic enzyme secretion in dogs, suggesting that endogenous cholecystokinin does not have a physiological role in regulating postprandial pancreatic enzyme secretion..$^{22}$ The reason for the discrepancy between that study and ours is not apparent. The results of our study are more in line with those of Konturek et al. ${ }^{17}$ They recently showed that the pancreatic protein output after an intragastric meal was inhibited by $70 \%$ in the first hour after administration of slightly lower doses of 0.5 and $1.0 \mu \mathrm{mol} / \mathrm{kg}$ per $\mathrm{h}$ of lorglumide than that of about $4 \mu \mathrm{mol} / \mathrm{kg}$ per $\mathrm{h}$ used in the present study. ${ }^{17}$ Interestingly, in the study of Konturek et al the higher dose did not provoke a more profound inhibition of mealstimulated pancreatic protein output. ${ }^{17}$ The latter finding may indicate that in their studies all cholecystokinin-receptors on the pancreas were blocked by the doses of the cholecystokininreceptor antagonist administered. Doseresponse studies with various doses of cholecystokinin-8 and lorglumide, however, showed that the doses of lorglumide used in the test meal study did not completely abolish the stimulation of pancreatic protein secretion by cholecystokinin. ${ }^{17}$ Unfortunately, the study of Konturek $e t$ $a l^{17}$ cannot be compared with ours in more detail since no plasma cholecystokinin concentrations were measured and therefore no attempt could be made to compare the effect of the meal with an appropriate dose of cholecystokinin. Furthermore, the study design was different from ours, since increasing doses of lorglumide were infused after the start of the cholecystokinin infusion, while in our study infusion of lorglumide was started one hour before the test meal stimulation. The finding that two recent studies using different designs have shown that the structurally unrelated cholecystokinin-receptor antagonist L-364,718 also inhibited test meal stimulated pancreatic enzyme secretion further supports the part that cholecystokinin plays in the regulation of postprandial pancreatic enzyme secretion. ${ }^{23} 24$

Since the inhibitory effect of lorglumide on bombesin-stimulated pancreatic protein secretion $(60 \%)$ was closely similar to that on the enzyme secretion stimulated by caerulein, it is unlikely that, apart from cholecystokinin, other factors contribute to the regulation of bombesinstimulated pancreatic enzyme secretion. This finding is in agreement with the study of Konturek et al using the non-peptide cholecystokinin-receptor antagonist L-364, 718. ${ }^{23}$ It is noteworthy that receptors for bombesin have not been identified on canine acinar cells, ${ }^{25}$ precluding extrapolation of the present findings to other species.

The finding that all three stimuli increase secretin-induced pancreatic bicarbonate secretion can be partly explained by the well established potentiation between cholecystokinin and secretin on bicarbonate output from the pancreas in the dog. ${ }^{23026}$ The significantly greater bicarbonate response to the meal than to caerulein stimulation suggests other mechanisms, possibly vagal-cholinergic reflexes originating in the stomach and small intestine. ${ }^{2371021}$

The finding that the bicarbonate response to bombesin is similar to that to caerulein suggests that the potentiation between cholecystokinin and secretin can fully account for this stimulation of pancreatic bicarbonate output during bombesin. The inhibition of pancreatic bicarbonate output by lorglumide was much smaller than that of enzyme secretion for all three stimuli. In fact, only inhibition of test meal stimulated pancreatic bicarbonate secretion was significant, whereas the inhibition of bicarbonate secretion during the infusions of bombesin and caerulein just failed to be significant. This finding suggests that cholecystokinin interacts with vagalcholinergic mechanisms activated by intragastric meal stimulation. Since the percentage inhibition by lorglumide of meal stimulated bicarbonate secretion (38\%) was similar to that found during stimulation with caerulein $(40 \%)$, the possibility that cholecystokinin mainly interacts with secretin in the regulation of meal stimulated pancreatic bicarbonate secretion cannot be excluded with certainty from the present study. In the study of Konturek et al the inhibition by lorglumide of test meal stimulated bicarbonate secretion failed to be significant in the first hour, but was significant in the second and third hour of their study. ${ }^{17}$

An interesting finding is that gastric acid output during infusion of caerulein and bombesin was increased by administration of lorglumide, suggesting that cholecystokinin acts as an inhibitor of gastric acid secretion during stimulation by these polypeptides. Recently, receptors for cholecystokinin have been identified on somatostatin producing D-cells in the mucosa of the gastric body. ${ }^{27}$ It is likely that lorglumide inhibits the stimulation of the D-cells by cholecystokinin, resulting in a reduced inhibition of acid secretion by somatostatin in the gastric body. Hildebrand et al have shown that another structurally related cholecystokinin-receptor antagonist, CR-1505, stimulated gastric acid secretion during infusion of cholecystokinin-8, but not during infusion of pentagastrin..$^{28}$

The present study suggests an important role for cholecystokinin in the stimulation of pancreatic enzyme secretion by bombesin and a test meal in the dog. Furthermore, endogenously released cholecystokinin seems to function as an inhibitor of gastric acid secretion during stimulation by bombesin and caerulein.

This study was supported by grant 13-37-43 from the Netherland Foundation for Medical Research MEDIGON and grant S 228/7-1 from the Deutsche Forschungsgemeinschaft. 
We are indebted to Mrs D Levin, Mrs G Albertz, Ms K Garlipp, and $\mathrm{Mr} I \mathrm{~J}$ Kuipers for technical assistance and to Louise Niepoth for secretarial help.

1 Yanaihara N, Yanaihara C, Mochizuki T, Iwahara K, Fujita T, Iwanga T. Immunoreactive GRP. Peptides 1981; 2: 18591.

2 Solomon TE. Regulation of pancreatic secretion. Clin Gastroenterol 1984; 13: 657-78.

3 Solomon TE. Control of exocrine pancreatic secretion. In: Johnson LR, ed. Physiology of the gastrointestinal tract. 2nd ed. New York: Raven Press, 1987: 1172-207.

4 De Jong AJL, Singer MV, Lamers CBHW. Effect of pancreatic polypeptide-antiserum on bombesin-stimulated pancreatic exocrine secretion in dogs. Peptides 1987; 8: 973-6.

5 Gardner JD, Jensen RT. Characterization of receptors for Gardner JD, Jensen RT. Characterization of receptors for
gastrointestinal peptides. Scand f Gastroenterol 1983: 18 gastrointestinal pep

6 De Jong AJL, Klamer M, Jansen JBMJ, Lamers CBHW. Effect of atropine and somatostatin on bombesin-stimulated plasma gastrin, cholecystokinin and pancreatic polypeptide in man. Regul Pept 1987; 17: 285-93.

7 Singer MV. Pancreatic secretory response to intestinal stimulants. Scand $\mathcal{F}$ Gastroenterol 1987; 22 (suppl 139): 1-13.

8 Setnikar I, Bani M, Cereda R, et al. Pharmacological characterisation of a new potent and specific nonpolypeptide cholecystokinin antagonist. Drug Res 1987; 37: 703-7.

9 Makovec F, Bani M, Cereda R, et al. Pharmacological properties of lorglumide as a member of a new class of properties of lorglumide as a member of a new clas
cholecystokinin antagonists. Drug Res 1987; 37: 1265-8.

10 Thomas JE. An improved cannula for gastric and intestinal fistulas. Proc Soc $\operatorname{Exp} \operatorname{Biol}(N Y)$ 1941; 46: 260-4

11 De Jong AJL, Singer MV, Lamers CBHW. Effect of rabbit anti-pancreatic polypeptide serum on postprandial pancreatic exocrine secretion in dogs. Gastroenterology 1986;90: 1926-31.

12 Jansen JBMJ, Lamers CBHW. Radioimmunoassay of cholecystokinin in human tissue and plasma. Clin Chim Acta 1983; 131: 305-16.

13 JBMJ Jansen, Lamers CBHW. Molecular forms of cholecystokinin in plasma from normal and gastrectomized 6 human

14 Beglinger C, Fried M, Whitehouse J, Jansen JB, Lamers CB, Gyr K. Pancreatic enzyme response to a liquid meal and to hormonal stimulation; correlation with plasma secretin and cholecystokinin levels. $\mathcal{F}$ Clin Invest 1985; 75: 1471-6.

15 Singer MV, Sarles H. Pancreatic dose-response curves to cholecystokinin determined by two techniques in dogs. Scand 7 Gastroenterol 1978; 13: 969-74.

16 Hildebrand P, Beglinger C, Köhler E, Senitkar I, Gyr K Biological effects of a proglumide derivata as cholecystokinin antagonist in conscious dogs. Regul Pept 1987; 18: 213-20.

17 Konturek SJ, Tasler J, Cieszkowski M, Szewczyk K, Hladij $M$. Effect of cholecystokinin receptor antagonist on pancreatic responses to exogenous gastrin and cholecystokini and to meal stimuli. Gastroenterology 1988; 94: 1014-23.

18 Singer MV, Solomon TE, Grossman MI. Effect of atropine on secretion from intact and transplanted pancreas in the dog. Am $\mathcal{F}$ Physiol 1980; 238: G18-22.

19 Singer MV, Solomon TE, Wood J, Grossman MI. Latency of pancreatic enzyme response to intraduodenal stimulants. Am $\mathcal{F}$ Physiol 1980; 238: G23-9.

20 Singer MV, Niebel W, Gotthold S, Hoffmeister D, Goebell H. Extrinsic nerves as mediators of the pancreatic secretory response to intravenous caerulein and intraduodenal response to intravenous caerulein and
tryptophan. Gastroenterology 1987; 92: 1642 .

tryptophan. Gastroenterology 1987; $92: 1642$.
21 Niebel W, Beglinger C, Singer MV. Pancreatic bicarbonate response to HCL before and after cutting the extrinsic nerves of the pancreas in dogs. Am $\mathcal{F}$ Physiol 1988; 254 G436-43.

22 Pendleton RG, Bendesky RJ, Schaffer L, Nolan TE, Gould RJ, Clineschmidt BV. Roles of endogenous cholecystokinin in biliary, pancreatic and gastric function: studies with L364,718 , a specific cholecystokinin receptor antagonist. f Pharmacol Exp Ther 1987; 241: 110-6.

23 Konturek SJ, Tasler J, Konturek JW, et al. Effects of nonpeptidal CCK receptor antagonist (L-364718) on pancreatic responses to cholecystokinin, gastrin, bombesin, and meat responses to cholecystokinin, gastrin
feeding in dogs. Gut 1989; 30: 110-7.

24 Hosotani R, Chowdhury P, Rayford PL. L-364,718, a new CCK antagonist, inhibits postprandial pancreatic secretion and PP release in dogs. Dig Dis Sci 1989; 34: 462-7.

25 Bommelaer G, Rozental G, Bernier C, et al. Action of secretagoques on amylase release from the dog pancreatic acini. Digestion 1981; 21: 248-54.

26 Beglinger C, Grossman MI, Solomon TE. Interaction between stimulants of exocrine pancreatic secretion in dogs. Am $\mathcal{F}$ Physiol 1984; 246: G173-9.

27 Soll AH, Amirian DA, Park J, Elashoff JD, Yamada T. Cholecystokinin potently releases somatostatin from canine fundic mucosal cells in short-term culture. Am $\mathcal{F}$ Physiol fundic mucosal cells

28 Hildebrand P, Beglinger C, Köhler E, Setnikar I, Gyr K. Biological effects of a proglumide derivative as cholecystokinin antagonist in conscious dogs. Regul Pept 1987 18: 213-20. 